\title{
Use of a Reinforced Triple-row Stapler Following Distal Pancreatectomy Reduces the Incidence of Postoperative Pancreatic Fistula in Patients With a High BMI
}

\author{
HIROMICHI KAWAIDA, HIROSHI KONO, HIDETAKE AMEMIYA, NAOHIRO HOSOMURA, \\ RYO SAITO, KAZUNORI TAKAHASHI, ATSUSHI YAMAMOTO, MITSUAKI WATANABE, \\ SHINJI FURUYA, HIROKI SHIMIZU, HIDENORI AKAIKE, YOSHIHIKO KAWAGUCHI, \\ MAKOTO SUDO, MASANORI MATUSDA, JUN ITAKURA, HIDEKI FUJII and DAISUKE ICHIKAWA \\ First Department of Surgery, Faculty of Medicine, University of Yamanashi, Yamanashi, Japan
}

\begin{abstract}
Background/Aim: Although perioperative management and operative techniques for pancreatic surgery have improved, postoperative pancreatic fistula (POPF) remains the major cause of morbidity and mortality following distal pancreatectomy (DP). The purpose of this study was to evaluate the superiority of the reinforced stapler compared to the bare triple row stapler. Patients and Methods: A total of 93 patients who underwent DP at the First Department of Surgery at Yamanashi University were examined. The patients were divided into two groups according to the closure method for the pancreatic stump; the bare triple-row stapler (BTRS) group and the reinforced triple-row stapler (RTRS) group. The postoperative outcomes were then compared in terms of several clinicopathological factors between the two groups. Results: Seven patients were diagnosed with Grade B/C POPF in this series. The incidence of POPF in the RTRS group was lower than that in the BTRS group (3.6\% vs. 13.5\%), although there was no significant difference $(p=0.077)$. Further detailed analysis demonstrated that RTRS significantly reduced POPF compared to BTRS in obese patients with a BMI $>25.0 \mathrm{~kg} / \mathrm{m}^{2}$ $(p=0.038)$. Conclusion: Reinforced triple-row staplers may reduce the incidence of severe POPF, especially in obese patients with a $B M I>25 \mathrm{~kg} / \mathrm{m}^{2}$.
\end{abstract}

Distal pancreatectomy (DP) is generally performed for borderline or malignant pancreatic body and tail neoplasms.

Correspondence to: Hiromichi Kawaida, MD, Ph.D., First Department of Surgery, Faculty of Medicine, University of Yamanashi, 1110 Shimokato, Chyuo-shi, Yamanashi, 409-3898 Japan. Tel/Fax: +81 552737390, e-mail: kawaidah@yamanashi.ac.jp, Clinical trial registration number: UMIN000033687

Key Words: Reinforced triple-row stapler, postoperative pancreatic fistula, body mass index.
Although perioperative management and operative techniques for pancreatic surgery have improved, postoperative pancreatic fistula (POPF) remains the major cause of morbidity and mortality following DP, occurring in 5-32\% of all cases (1-7) based on the International Study Group of Pancreatic Fistula (ISGPF) criteria $(8,9)$. Therefore, several surgical techniques have been evaluated to reduce the incidence POPF.

POPF causes fever, abdominal pain, and abdominal abscess, and sometimes develops into pseudoaneurysm, causing lethal intraperitoneal hemorrhage. In addition, it will increase the hospital stay and hospitalization costs. In addition, it will delay adjuvant therapy for malignant pancreatic tumors, which may affect the long-term outcomes of patients.

Recently, surgical staplers are commonly used for distal pancreatectomy. The use of staplers for closure has a lower POPF rate than hand-sewn closure. However, the DISPACT trial failed to confirm the superiority of stapler closure to hand-sewn closure (3), and the incidence of POPF remains high. Therefore, the mesh reinforced stapler is expected to reduce the incidence of POPF. Recently, the safety of the reinforced triple-row stapler was reported (10), but its efficacy is controversial.

The purpose of this study was to evaluate the superiority of the reinforced stapler compared with the bare triple row stapler.

\section{Patients and Methods}

Patients. A total of 93 patients who underwent DP at the First Department of Surgery at Yamanashi University between April 2013 and March 2018 were examined. This study was reviewed and approved by the ethics committee of the University of Yamanashi. To reduce the incidence of POPF following DP, we introduced the reinforced triple-row stapler for management of the pancreatic stump. The patients were divided into two groups, the bare triple- 
Table I. Characteristics of enrolled patients and intraoperative findings.

\begin{tabular}{|c|c|c|c|}
\hline & $\begin{array}{l}\text { Triple-row stapler }(\mathrm{n}=37) \\
\qquad(\mathrm{n}=37)\end{array}$ & $\begin{array}{l}\text { Reinforcement }(\mathrm{n}=56) \\
(\mathrm{n}=56)\end{array}$ & $\begin{array}{c}\text { Univariate analysis } \\
p \text {-value }\end{array}$ \\
\hline \multicolumn{4}{|l|}{ Preoperative status } \\
\hline Age & $66.1 \pm 2.5$ & $62.9 \pm 2.0$ & 0.318 \\
\hline Gender (male/female) & $19 / 18$ & $18 / 38$ & \\
\hline BMI $\left(\mathrm{kg} / \mathrm{m}^{2}\right)$ & $22.0 \pm 0.7$ & $22.1 \pm 0.5$ & 0.361 \\
\hline $\operatorname{HbA1c}(\%)$ & $5.9 \pm 0.1$ & $6.4 \pm 0.1$ & 0.052 \\
\hline \multicolumn{4}{|l|}{ Histopathological diagnosis } \\
\hline Pancreatic adenocarcinoma & $16(43.2 \%)$ & $21(37.5 \%)$ & \\
\hline IPMN & $10(27.0 \%)$ & $9(16.1 \%)$ & \\
\hline PNET & $6(16.2 \%)$ & $14(25.0 \%)$ & \\
\hline $\mathrm{MCN}$ & $1(2.7 \%)$ & $4(7.1 \%)$ & \\
\hline $\mathrm{SCN}$ & $1(2.7 \%)$ & $1(1.8 \%)$ & \\
\hline SPN & 0 & $3(5.4 \%)$ & \\
\hline Other diseases & $3(8.1 \%)$ & $4(7.1 \%)$ & \\
\hline Benign disease/Malignant disease & $17 / 20$ & $30 / 26$ & 0.477 \\
\hline \multicolumn{4}{|l|}{ Performed operation } \\
\hline \multicolumn{4}{|l|}{ DP } \\
\hline +Splenectomy (yes/no) & $28 / 9$ & $29 / 27$ & 0.021 \\
\hline +Lymph node dissection (D0,1/D2) & $19 / 18$ & $29 / 27$ & 0.968 \\
\hline +Gastrectomy & 2 & 2 & \\
\hline +Colectomy & 1 & 2 & \\
\hline Laparo/Open & $9 / 28$ & $24 / 32$ & 0.069 \\
\hline Duration of operation (min) & $349.5 \pm 22.4$ & $403.2 \pm 14.4$ & 0.037 \\
\hline Blood loss (ml) & $686.2 \pm 84.4$ & $714.1 \pm 91.4$ & 0.832 \\
\hline $\mathrm{RBC}$ transfusion (yes/no) & $3 / 34$ & $5 / 51$ & \\
\hline Thickness of the Stump & $13.2 \pm 0.6$ & $13.5 \pm 0.5$ & 0.713 \\
\hline Width of the Stump & $31.7 \pm 1.2$ & $30.1 \pm 1.0$ & 0.336 \\
\hline POPF Grade B+C & $5(13.5 \%)$ & $2(3.6 \%)$ & 0.077 \\
\hline
\end{tabular}

BMI: Body mass index; HbA1c: hemoglobin A1c; IPMN: intraductal papillary mucinous neoplasm; PNET: pancreatic neuroendocrine tumor; MCN: mucinous cyst neoplasm; SCN: serous cyst adenoma; SPN; solid-pseudopapillary neoplasm; DP: distal pancreatectomy; RBC: red blood cell; POPF: postoperative pancreatic fistula; POPF is defined based on ISGPF.

row stapler (BTRS) group and the reinforced triple-row stapler (RTRS) group, and data were collected prospectively. The clinical characteristics and pathological examinations were collected from electronic medical records. Among the patients included in this study, none had a history of pancreatitis that affected the remaining pancreas. To supplement the perioperative data, a review of the surgical and anesthetic charts of each patient was performed. The patient characteristics are shown in Table I. Patients were not required to give informed consent to the study because the analysis used anonymous clinical data that were obtained after each patient agreed to treatment by written consent.

Surgical techniques. After dissection of the peripancreatic space, the pancreas was divided using the bare triple-row stapler (Endo GIA ${ }^{\mathrm{TM}}$ Reloads with Tri-Staple ${ }^{\mathrm{TM}}$ Technology $60 \mathrm{~mm}$; COVIDIEN, North Haven, CT, USA) or reinforced triple-row stapler (the Endo GIA ${ }^{\mathrm{TM}}$ Reinforced Reload with Tri-Staple ${ }^{\mathrm{TM}}$ Technology $60 \mathrm{~mm}$; COVIDIEN, North Haven, CT, USA). The cartridge height of the stapler was selected according to the thickness of the pancreatic cutting line. The thickness of the pancreatic cutting line was measured by intraoperative ultrasonography. A black cartridge was used for a thickness of $11 \mathrm{~mm}$ or more, and a purple cartridge was used for a thickness of less than $11 \mathrm{~mm}$. The closure jaw was clamped slowly and carefully for $5 \mathrm{~min}$, and the pancreas was cut little by little over $15 \mathrm{~min}$ in order to reduce damage to the pancreatic parenchyma and then the staples were applied. The stapler was not released immediately after firing. After removing the resected pancreas, a closed drain was placed near the stump of the remaining pancreas. Intraoperative data are also shown in Table I.

Perioperative management. To prevent bacterial infection, second generation cefem antibiotics were used either intraoperatively or for 3 days postoperatively. Prophylactic somatostatin analogues were not administered to prevent POPF. The drainage tube was removed when the drainage fluid was clear until postoperative day (POD)3, regardless of the amount of drainage fluid, indicating no bacterial infection.

POPF was divided into two groups (No POPF and Grade B/C POPF). Patients with Grade A were included in the No POPF group because POPF Grade A is negligible due to its minimal clinical importance (9), whereas Grade B and C are clinically important. POPF was diagnosed according to the International Study Group of Pancreatic Fistula (ISGPF) criteria (8). The patients were also divided into two groups according to the closure method for the pancreatic stump, the bare triple-row stapler group or the reinforced triple-row stapler group, and all clinicopathological factors were compared between these two groups. 
Table II. Comparison between POPF B/C group and No POPF group.

\begin{tabular}{|c|c|c|c|}
\hline & $\begin{array}{l}\text { Grade B/C POPF } \\
\quad(\mathrm{n}=77.5 \%)\end{array}$ & $\begin{array}{c}\text { BL } \\
(\mathrm{n}=8692.5 \%)\end{array}$ & $\begin{array}{c}\text { Univariate analysis } \\
p \text {-Value }\end{array}$ \\
\hline \multicolumn{4}{|l|}{ Preoperative status } \\
\hline Age & $56.4 \pm 5.6$ & $64.8 \pm 1.6$ & 0.154 \\
\hline Gender (male/female) & 43222 & $32 / 54$ & 0.077 \\
\hline BMI $\left(\mathrm{kg} / \mathrm{m}^{2}\right)$ & $26.8 \pm 0.5$ & $22.2 \pm 0.4$ & 0.003 \\
\hline HbA1c $(\%)$ & $5.8 \pm 0.2$ & $6.2 \pm 0.1$ & 0.24 \\
\hline \multicolumn{4}{|l|}{ Histopathological diagnosis } \\
\hline Pancreatic adenocarcinoma & $2(28.6 \%)$ & $35(40.7 \%)$ & \\
\hline IPMN & 0 & $19(22.1 \%)$ & \\
\hline PNET & $3(42.9 \%)$ & $17(19.8 \%)$ & \\
\hline $\mathrm{MCN}$ & $1(14.3 \%)$ & $4(4.7 \%)$ & \\
\hline $\mathrm{SCN}$ & 0 & $2(2.3 \%)$ & \\
\hline SPN & 0 & $3(3.5 \%)$ & \\
\hline Other diseases & $1(14.3 \%)$ & $6(7.0 \%)$ & \\
\hline Benign disease/Malignant disease & $4 / 3$ & $43 / 43$ & 0.979 \\
\hline \multicolumn{4}{|l|}{ Neo adjuvant } \\
\hline None/NAC/NACRT & $7 / 0 / 0$ & $83 / 2 / 1$ & \\
\hline \multicolumn{4}{|l|}{ Intraoperative findings } \\
\hline \multicolumn{4}{|l|}{ Performed operation } \\
\hline \multicolumn{4}{|l|}{$\mathrm{DP}$} \\
\hline+ Splenectomy $($ yes/no $)$ & $3 / 4$ & $54 / 32$ & 0.303 \\
\hline +Lymph node dissection(D0,1/D2) & $5 / 2$ & $43 / 43$ & 0.280 \\
\hline +Gastrectomy & 0 & 4 & \\
\hline +Colectomy & 0 & 3 & \\
\hline Laparoscopy (yes/no) & $1 / 6$ & $32 / 54$ & 0.227 \\
\hline Tri-stapler/Reinforcement & $5 / 2$ & $32 / 54$ & 0.077 \\
\hline Duration of operation(min) & $427.9 \pm 44.8$ & $378.1 \pm 13.2$ & 0.302 \\
\hline Blood loss (ml) & $1084.0 \pm 242.2$ & $672.0 \pm 65.8$ & 0.090 \\
\hline RBC transfusion(yes/no) & $0 / 7$ & 7/79 & \\
\hline Thickness of the Stump & $14.9 \pm 2.1$ & $13.2 \pm 0.4$ & 0.282 \\
\hline Width of the Stump & $34.9 \pm 2.7$ & $30.4 \pm 0.8$ & 0.135 \\
\hline
\end{tabular}

POPF: Postoperative pancreatic fistula; BMI: body mass index; HbA1c: hemoglobin A1c; IPMN: intraductal papillary mucinous neoplasm; PNET: pancreatic neuroendocrine tumor; MCN: mucinous cyst neoplasm; SCN: serous cyst adenoma; SPN; solid-pseudopapillary neoplasm; NAC: neoadjuvant chemotherapy; NACRT: neoadjuvant chemoradiotherapy; DP: distal pancreatectomy; RBC: red blood cell.

Statistical analysis. Data were expressed as the mean \pm standard deviation. Patient characteristics, and intraoperative and postoperative factors between the two groups were compared using Chi-square statistics, Fisher's exact test, and the Mann-Whitney $U$-test. Significance was defined as a $p$-value $<0.05$. The statistical analyses were performed using SPSS version 23.0 software (SPSS Inc, Chicago, IL, USA).

\section{Results}

Incidence of POPF. Of the 93 patients who underwent DP, the bare triple-row stapler was used in 37 patients between April 2013 and March 2015 (bare triple-row stapler group) and the reinforced triple-row stapler was used in 56 patients between April 2015 and March 2018 (reinforced triple-row stapler group) to close the pancreatic stump. All surgeries were performed by pancreatic surgeons with more than 15 years of experience.
There were no significant differences in patient demographics or clinicopathological factors between the two groups. There were also no significant differences in intraoperative findings, including the thickness and width of the stump. Laparoscopic surgery was performed more frequently in the reinforcement group, but there was no significant difference. In total, 7 patients were diagnosed with Grade B/C POPF. There were no patients who were re-hospitalized due to late-onset POPF and there were no postoperative deaths. The incidence of POPF in the reinforced triple-row stapler group was lower than that in the bare triple-row stapler group $(3.6 \%$ vs. $13.5 \%)$, but the difference was not significant $(p=0.077)$ (Table I). No patient developed bleeding from the pancreatic stump after surgery or intraperitoneal hemorrhage due to POPF.

Risk factors for POPF. The enrolled patients were classified into two groups: the POPF Grade $\mathrm{B} / \mathrm{C}$ group or no POPF 
Table III. Characteristics of the enrolled patients in BMI high group.

\begin{tabular}{|c|c|c|c|}
\hline & $\begin{array}{c}\text { Triple-row stapler } \\
\qquad(\mathrm{n}=9)\end{array}$ & $\begin{array}{c}\text { Reinforcement } \\
(\mathrm{n}=14)\end{array}$ & $\begin{array}{c}\text { Univariate analysis } \\
p \text {-value }\end{array}$ \\
\hline \multicolumn{4}{|l|}{ Preoperative status } \\
\hline Age & $62.3 \pm 5.1$ & $63.1 \pm 4.5$ & 0.909 \\
\hline Gender (male/female) & $6 / 3$ & $7 / 7$ & 0.454 \\
\hline BMI $\left(\mathrm{kg} / \mathrm{m}^{2}\right)$ & $26.5 \pm 0.4$ & $27.9 \pm 0.6$ & 0.106 \\
\hline $\operatorname{HbA1c}(\%)$ & $6.0 \pm 0.4$ & $6.3 \pm 0.1$ & 0.431 \\
\hline \multicolumn{4}{|l|}{ Histopathological diagnosis } \\
\hline Pancreatic adenocarcinoma & $4(44.4 \%)$ & $4(28.6 \%)$ & \\
\hline IPMN & $1(11.1 \%)$ & $1(7.1 \%)$ & \\
\hline PNET & $2(22.2 \%)$ & $7(50.0 \%)$ & \\
\hline $\mathrm{MCN}$ & $1(11.1 \%)$ & $1(7.1 \%)$ & \\
\hline $\mathrm{SCN}$ & 0 & 0 & \\
\hline SPN & 0 & $1(7.1 \%)$ & \\
\hline Other diseases & $1(11.1 \%)$ & 0 & \\
\hline Benign disease/Malignant disease & $4 / 5$ & $10 / 4$ & 0.477 \\
\hline \multicolumn{4}{|l|}{ Performed operation } \\
\hline \multicolumn{4}{|l|}{ DP } \\
\hline +Splenectomy (yes/no) & $6 / 3$ & $5 / 9$ & 0.161 \\
\hline+ Lymph node dissection (D0,1/D2) & $5 / 4$ & $10 / 4$ & 0.458 \\
\hline +Gastrectomy & 0 & 0 & \\
\hline +Colectomy & 0 & 0 & \\
\hline Laparo/Open & $2 / 7$ & $7 / 7$ & 0.199 \\
\hline Duration of operation (min) & $395.8 \pm 34.5$ & $419.1 \pm 27.9$ & 0.605 \\
\hline Blood loss $(\mathrm{ml})$ & $994.3 \pm 240.2$ & $530.9 \pm 128.0$ & 0.077 \\
\hline RBC transfusion (yes/no) & $3 / 34$ & $5 / 51$ & \\
\hline Thickness of the stump & $12.2 \pm 1.2$ & $15.4 \pm 1.0$ & 0.062 \\
\hline Width of the stump & $31.3 \pm 3.3$ & $31.4 \pm 1.8$ & 0.979 \\
\hline
\end{tabular}

BMI: Body mass index; HbA1c: hemoglobin A1c; IPMN: intraductal papillary mucinous neoplasm; PNET: pancreatic neuroendocrine tumor; MCN: mucinous cyst neoplasm; SCN: serous cyst adenoma; SPN: solid-pseudopapillary neoplasm; DP: distal pancreatectomy; RBC: red blood cell.

group. As a result, the only independent risk factor for POPF after DP in the enrolled patients was the body mass index (BMI) $(p=0.003)$. Age, sex, HbA1c, operative time, performed operation, blood loss, and thickness and width of the stump were not significant risk factors in our study (Table II).

Analysis of POPF in the high-risk group. Based on the above results, the correlation between the clinicopathological factors and occurrence of Grade B/C POPF was re-analyzed in the 23 patients with a BMI $>25.0 \mathrm{~kg} / \mathrm{m}^{2}$. Nine patients underwent DP with the bare triple-row stapler and 14 patients underwent DP with the reinforced triple-row stapler. No significant differences in patient characteristics, histopathological findings, performed operation, or intraoperative findings were found between two groups. The BMI, which is a risk factor for POPF, was slightly higher in the reinforced group. Furthermore, the stump of the pancreas was thicker in the reinforced group (Table III). POPF, however, occurred in 5 patients $(55.6 \%)$ for whom the bare triple-row stapler was used, whereas POPF only occurred in 2 patients $(14.3 \%)$ for whom the reinforced triple-row stapler was used even though the overall BMI was higher in the
Table IV. Comparison of POPF according to stump closure.

\begin{tabular}{lccc}
\hline & $\begin{array}{c}\text { Triple-row } \\
\text { stapler } \\
(\mathrm{n}=9)\end{array}$ & $\begin{array}{c}\text { Reinforcement } \\
(\mathrm{n}=14)\end{array}$ & $\begin{array}{c}\text { Univariate } \\
\text { analysis } \\
p \text {-value }\end{array}$ \\
\hline Grade B/C POPF & 5 & 2 & 0.038 \\
\hline
\end{tabular}

POPF: Postoperative pancreatic fistula.

reinforced group. The use of the reinforced triple-row stapler significantly reduced the incidence of POPF compared to the use of the bare triple-row stapler $(p=0.038)$ in the high BMI group, as shown in Table IV.

\section{Discussion}

POPF remains a significant cause of morbidity following DP, and is a serious complication that may lead to surgery-related death. Several techniques have been applied in an effort to reduce the incidence of POPF, including ligation of the main 
pancreatic duct $(11)$, biological glues $(12,13)$ and stapler devices $(14,15)$. However, the most appropriate closure technique for the pancreatic stump during DP remains controversial.

Stapler closure for DP has become a widely used method because of its convenience. A recent study found that the use of a reinforced stapler for distal pancreatectomy was safe (10). Several studies demonstrated that the use of the reinforcement triple-row stapler significantly reduced the incidence of POPF compared with the use of the bare triplerow stapler (16-20). On the other hand, there are also reports showing no significant difference $(10,21,22)$, and reports showing that the incidence of POPF was increased (23).

Therefore, in this study, the POPF rates following usage of the bare stapler and reinforced triple-row stapler after DP were compared. It was found that clinically relevant POPF (grades B and C) occurred in $13.5 \%$ of cases following the use of the bare triple-row stapler and in $3.6 \%$ of patients following usage of the reinforced triple-row stapler. By using the reinforced triple-row stapler, the incidence of POPF was reduced to approximately a quarter compared with that following usage of the bare triple-row stapler for DP, but no significant difference was noted.

Several studies have reported that a high BMI is a risk factor for POPF $(5,24-26)$. Indeed, in our study, BMI was the only independent risk factor for POPF. Seeliger et al. reported that $\mathrm{BMI}>25.0 \mathrm{~kg} / \mathrm{m}^{2}$ was the only significant indicator for POPF (5), and in our study, all patients with clinical POPF had BMI $>25.0 \mathrm{~kg} / \mathrm{m}^{2}$.

Based on these data, only patients with a BMI $>25.0$ $\mathrm{kg} / \mathrm{m}^{2}$ were selected and examined. As a result, the incidence of POPF was significantly reduced in the reinforced triplerow stapler group compared with the bare tri-stapler group. The incidence of POPF was not considered to be significant because low-risk patients were included regardless of the stapler used. In other words, the reinforced triple-row stapler was better for the high-risk group with a BMI $>25.0 \mathrm{~kg} / \mathrm{m}^{2}$.

Several risk factors for POPF have been reported, including the thickness of the pancreatic cut and hard pancreatic parenchyma $(2,4,27)$. Conversely, there are reports suggesting that a soft pancreas is a risk factor (28). Moreover, a lower staple height may cause laceration or dehiscence of hard or thick pancreatic parenchyma, whereas a higher staple height may not seal the pancreatic parenchyma completely, resulting in leakage or bleeding from the pancreatic stump $(20,21,29)$. Although proper cartridge selection for pancreatic thickness is controversial, it is suggested that intraoperative ultrasound examinations to measure the thickness of the pancreatic cutting line are important because they can increase accuracy. It is also important to cut the pancreas carefully to prevent laceration or dehiscence of the pancreas because the pancreatic cutting line is sealed more gently.
A recent study reported that the use of the reinforced triple-row stapler for DP was safe, but the efficacy of reinforced triple-row staplers in reducing clinically relevant POPF was not clarified (10). Our study suggests that stump closure by a reinforced stapler can reduce the incidence of clinically relevant POPF. However, the selection criteria for cartridges based on the thickness and hardness of the pancreas, the time and method of pre-decompression, and the time taken to cut the pancreas are unclear. These problems need to be solved, and a standardized method is desired to perform pancreatic closure in DP more safely.

\section{Conclusion}

This study demonstrated that reinforced triple-row staplers may reduce the incidence of severe POPF, especially in obese patients with a BMI $>25.0 \mathrm{~kg} / \mathrm{m}^{2}$.

\section{Authors' Contributions}

All Authors helped to perform the research; Kawaida $\mathrm{H}$ actively involved in this study especially in statistical design. Concept and clinical design were conducted by 5 surgeons (Kawaida $\mathrm{H}$, Hosomura N, Amemiya H, Kono $\mathrm{H}$ and Ichikawa D). Acquisition of data was done by all physician (Kawaida H, Kono H, Amemiya H, Hosomura N, Saito R, K Takahashi, Yamamoto A, Watanabe M, Furuya S, Shimizu H, Akaike H, Kawaguchi Y, Sudo M, M Matsuda, Itakura J, Fujii H, Ichikawa D). Interpretation of data, and drafting the article was done by H. Kawaida. Finally, this article was revised and approved by all 17 investigators. Thus, all 17 authors actively participated in this study.

\section{Conflicts of Interest}

Hiromichi Kawaida and the other co-authors declare that they have no conflicts of interest regarding this study.

\section{References}

1 Sugimoto M, Gotohda N, Kato Y, Takahashi S, Kinoshita T, Shibasaki H, Nomura S, Konishi M and Kaneko H: Risk factor analysis and prevention of postoperative pancreatic fistula after distal pancreatectomy with stapler use. J Hepatobiliary Pancreat Sci 20: 538-544, 2013.

2 Okano K, Oshima M, Kakinoki K, Yamamoto N, Akamoto S, Yachida S, Hagiike M, Kamada H, Masaki T and Suzuki Y: Pancreatic thickness as a predictive factor for postoperative pancreatic fistula after distal pancreatectomy using an endopath stapler. Surg Today 43: 141-147, 2013.

3 Diener MK1, Seiler CM, Rossion I, Kleeff J, Glanemann M, Butturini G, Tomazic A, Bruns CJ, Busch OR, Farkas S, Belyaev O, Neoptolemos JP, Halloran C, Keck T, Niedergethmann M, Gellert K, Witzigmann H, Kollmar O, Langer P, Steger U, Neudecker J, Berrevoet F, Ganzera S, Heiss MM, Luntz SP, Bruckner T, Kieser M and Büchler MW: Efficacy of stapler versus hand-sewn closure after distal pancreatectomy (DISPACT): a randomised, controlled multicentre trial. Lancet 377: 1514-1522, 2011. 
4 Eguchi H1, Nagano H, Tanemura M, Takeda Y, Marubashi S, Kobayashi S, Wada H, Umeshita K, Mori M and Doki Y: A thick pancreas is a risk factor for pancreatic fistula after a distal pancreatectomy: selection of the closure technique according to the thickness. Dig Surg 28: 50-56, 2011.

5 Seeliger H1, Christians S, Angele MK, Kleespies A, Eichhorn ME, Ischenko I, Boeck S, Heinemann V, Jauch KW and Bruns CJ: Risk factors for surgical complications in distal pancreatectomy. Am J Surg 200: 311-317, 2010.

6 Lillemoe KD, Kaushal S, Cameron JL, Sohn TA, Pitt HA and Yeo CJ: Distal pancreatectomy: Indications and outcomes in 235 patients. Ann Surg 229: 693-700, 1999.

7 Kawaida H, Kono H, Watanabe M, Hosomura N, Amemiya H and Fujii H: Risk factors of postoperative pancreatic fistula after distal pancreatectomy using a triple-row stapler. Surg Today 48 : 95-100, 2018.

8 Bassi C1, Dervenis C, Butturini G, Fingerhut A, Yeo C, Izbicki J, Neoptolemos J, Sarr M, Traverso $W$ and Buchler M: International Study Group on Pancreatic Fistula Definition. Postoperative pancreatic fistula: an international study group (ISGPF) definition. Surgery 138: 8-13, 2005.

9 Bassi C, Marchegiani G, Dervenis C, Sarr M, Abu Hilal M, Adham M, Allen P, Andersson R, Asbun HJ, Besselink MG, Conlon K, Del Chiaro M, Falconi M, Fernandez-Cruz L, Fernandez-Del Castillo C, Fingerhut A, Friess H, Gouma DJ, Hackert T, Izbicki J, Lillemoe KD, Neoptolemos JP, Olah A, Schulick R, Shrikhande SV, Takada T, Takaori K, Traverso W, Vollmer CR, Wolfgang CL, Yeo CJ, Salvia R and Buchler M: International Study Group on Pancreatic Surgery (ISGPS). The 2016 update of the International Study Group (ISGPS) definition and grading of postoperative pancreatic fistula: 11 Years After. Surgery 161: 584-591, 2017.

10 Kawai M, Hirono S, Okada KI, Satoi S, Yanagimoto H, Kon M, Murakami $\mathrm{Y}$, Kondo $\mathrm{N}$, Sho $\mathrm{M}$, Akahori T, Toyama $\mathrm{H}$, Fukumoto T, Fujii T, Matsumoto I, Eguchi H, Ikoma H, Takeda Y, Fujimoto $\mathbf{J}$ and Yamaue $\mathrm{H}$ : Reinforced staplers for distal pancreatectomy. Langenbecks Arch Surg 402: 1197-1204, 2017.

11. Bilimoria MM, Cormier JN, Mun Y, Lee JE, Evans DB and Pisters PWT: Pancreatic leak after left pancreatectomy is reduced following main pancreatic duct ligation. Br J Surg 90: 190-196, 2003.

12 Fisher WE, Chai C, Hodges SE, Wu MF, Hilsenbeck SG and Brunicardi FC: Effect of BioGlue ${ }^{\circledR}$ on the incidence of pancreatic fistula following pancreas resection. J Gastrointest Surg 12: 882-890, 2008.

13 Suc B, Msika S, Fingerhut A, Fourtanier G, Hay JM, Holmières F, Sastre B and Fagniez PL: Temporary fibrin glue occlusion of the main pancreatic duct in the prevention of intra-abdominal complications after pancreatic resection: prospective randomized trial. Ann Surg 237: 57-65, 2003.

14 Ferrone CR1, Warshaw AL, Rattner DW, Berger D, Zheng H, Rawal B, Rodriguez R, Thayer SP and Fernandez-del Castillo C: Pancreatic fistula rates after 462 distal pancreatectomies: staplers do not decrease fistula rates. J Gastrointest Surg 12: 1691-1698, 2008.

15 Diener MK, Knaebel HP, Witte ST, Rossion I, Kieser M, Buchler MW and Seiler CM: Effectiveness of stapler versus hand-sewn closure after distal pancreatectomy (DISPACT trial): a randomized, controlled multicentre trial. Lancet 377: 1514-1522, 2011.

16 Hayashibe A and Ogino N: Clinical study for pancreatic fistula after distal pancreatectomy with mesh reinforcement. Asian J Surg 41: 236-240, 2018
17 Yamashita YI, Tsujita E, Chikamoto A, Imai K, Kaida T, Yamao T, Umezaki N, Nakagawa S, Hashimoto D and Baba H: Linear Stapling Device with Pre-attached Bioabsorbable Polyglycolic Acid Felt Reduces Postoperative Pancreatic Fistula After Distal Pancreatectomy. Anticancer Res 37: 1865-1868, 2017.

18 Kurahara H, Maemura K, Mataki Y, Sakoda M, Iino S, Hiwatashi $\mathrm{K}$, Ishigami S, Ueno S, Shinchi $\mathrm{H}$ and Natsugoe S: Closure of the pancreas in distal pancreatectomy: comparison between bare stapler and reinforced stapler. Hepatogastroenterology 61: 2367-2370, 2014.

19 Jensen EH, Portschy PR, Chowaniec J and Teng M: Metaanalysis of bioabsorbable staple line reinforcement and risk of fistula following pancreatic resection. J Gastrointest Surg 17: 267-272, 2013

20 Hamilton NA1, Porembka MR, Johnston FM, Gao F, Strasberg SM, Linehan DC and Hawkins WG: Mesh reinforcement of pancreatic transection decreases incidence of pancreatic occlusion failure for left pancreatectomy: a single-blinded, randomized controlled trial. Ann Surg 255: 1037-1042, 2012.

21. Subhedar PD1, Patel SH, Kneuertz PJ, Maithel SK, Staley CA, Sarmiento JM, Galloway JR and Kooby DA: Risk factors for pancreatic fistula after stapled gland transection. Am Surg 77: 965-970, 2011.

22 Johnston FM1, Cavataio A, Strasberg SM, Hamilton NA, Simon PO Jr, Trinkaus K, Doyle MB, Mathews BD, Porembka MR, Linehan DC and Hawkins WG: The effect of mesh reinforcement of a stapled transection line on the rate of pancreatic occlusion failure after distal pancreatectomy: review of a single institution's experience. HPB (Oxford) 11: 25-31, 2009.

23 Guzman EA1, Nelson RA, Kim J, Pigazzi A, Trisal V, Paz B and Di Ellenhorn J: Increased incidence of pancreatic fistulas after the introduction of a bioabsorbable staple line reinforcement in distal pancreatic resections. Am Surg 75: 954-957, 2009.

24 Nakamura M, Shindo K, Ideno N, Ueda J, Takahata S, Nakashima H, Ohtsuka T, Shimizu S, Oda Y and Tanaka M: Prediction of pancreatic fistula by preoperatively assessable factors; retrospective review of unified operations by single surgeon. Hepatogastroenterology 61: 834-837, 2014.

25 Ferrone CR1, Warshaw AL, Rattner DW, Berger D, Zheng H, Rawal B, Rodriguez R, Thayer SP and Fernandez-del Castillo C: Pancreatic fistula rates after 462 distal pancreatectomies: staplers do not decrease fistula rates. J Gastrointest Surg 12: 1691-1697, 2008.

26 Sledzianowski JF, Duffas JP, Muscari F, Suc B and Fourtanier F: Risk factors for mortality and intra-abdominal morbidity after distal pancreatectomy. Surgery 137: 180-185, 2005.

27 Kawai M, Tani M, Okada K, Hirono S, Miyazawa M, Shimizu A, Kitahata Y and Yamaue H: Stump closure of a thick pancreas using stapler closure increases pancreatic fistula after distal pancreatectomy. Am J Surg 206: 352-359, 2013.

28 Kleeff J1, Diener MK, Z'graggen K, Hinz U, Wagner M, Bachmann J, Zehetner J, Müller MW, Friess H and Büchler MW: Distal pancreatectomy: risk factors for surgical failure in 302 consecutive cases. Ann Surg 245: 573-582, 2007.

29 Sepesi B, Moalem J, Galka E, Salzman P and Schoeniger LO: The influence of staple size on fistula formation following distal pancreatectomy. J Gastrointest Surg 16: 267-274, 2012.

Received December 17, 2018

Revised January 4, 2019

Accepted January 10, 2019 